\title{
Positive Reinforcer
}

National Cancer Institute

\section{Source}

National Cancer Institute. Positive Reinforcer. NCI Thesaurus. Code C41211.

A stimulus that increases the frequency of behavior that leads to its presentation. Things such as food, water, sex, and the opportunity to explore are usually considered as positive reinforcers. Also many dependence-producing drugs, such as cocaine, morphine, phencyclidine, barbiturates, ethanol and some volatile solvents serve as a positive reinforcer. 